\section{HEALTH EDUCATION ON THE INDUSTRIAL FRONT}

(Humphrey Milford, Oxford. 1943. Pp. 63. 8s. 6d.)

This stimulating little book contains five lectures given to the 1942 health education conference of the New York Academy of Medicine. The first by Cassius H. Watson discusses in general terms all the problems involved in the 'industralization' of the community in wartime, and this acts as an introduction to a more detailed discussion of the various aspects in the later lectures. Otto A. Bessey describes the arrangements necessary for adequate nutrition for the population. He implies that the industrial canteen has been more developed in this country than in the United States; and stresses that its importance is to make certain that the people get the right foods to maintain health and strength and not necessarily the ones they like most. Leonard Greenburg defines the work of the industrial medical officer. ' Our purpose is to control plant working conditions so that an optimum environment may be provided for the worker; an environment in which he can work with safety and under conditions which are not detrimental to his health. This portion of the problem may and usually is given the name of industrial hygiene, and includes such phases as plant sanitation, illumination, ventilation, safety provisions, occupational disease control, and many others. The second portion of the problem is essentially non-occupational and consists in the conservation of the health of the worker through general supervision, and by the prevention of physical defects, their early detection and correction. Finally, the third phase consists in the restoration of the worker to health and earning capacity as promptly as possible following accident or disease.

In considering mental problems and morale Lydia G. Guberson stresses that the doctor must be a good listener with considerable patience; and it will help him tremendously if he has a sincere interest in human beings and their almost innumerable difficulties. Lastly, Harold R. Baxter records that more Americans will die this year because of civilian accidents than were killed by the Germans in the first World War: the education of workers in the control of accidents in industry is therefore of the greatest importance.

To those who think about the purpose and development of industrial medicine, this book will give many ideas.

K. M. A. P.

\section{INTERIM REPORT OF THE SOCIAL AND PRE- VENTIVE MEDICINE COMMITTEE OF THE ROYAL COLLEGE OF PHYSICIANS}

(R.C.P. London. 1943. Pp. 32.)

This excellent interim report makes the following recommendations:

(i) That every medical school should establish a Department of Social and Preventive Medicine, the size and scope of the department depending upon the facilities and personnel available.

(ii) That this department should organize a modernized course in Social and Preventive Medicine to replace the present course in Public Health, which, as in the clinical subjects, should be a curriculum founded securely on the basic sciences, growing and expanding through the three clinical years.

(iii) That as well as theoretical teaching such a curri- culum should bring the student into close touch with the active organizations in the community concerned, particularly with social and preventive medicine-namely, the health services provided by the local authorities, and the almoner's department within the hospital.

(iv) That all medical schools should recognize the importance of problems associated with industrial medicine.

(v) That student health services should be available in every medical school and that under the general direction of the head of the department of social and preventive medicine they should be used as an instrument of teaching.

(vi) That all teaching hospitals should employ properly trained almoners and psychiatric social workers, both in the care of patients and in the teaching of students.

(vii) That the Royal College of Physicians should take an active interest in the organization of the teaching of social and preventive medicine, not only to medical students, but also to nurses and medical social workers.

To-day the average doctor has little or no idea what conditions are likely in a factory, and therefore he is not capable of deciding if a man's job has any relation to the symptoms he complains of, and if so what action should be taken. It is not surprising therefore that complaints come from many industries about incompetent medical certification. This is not the fault of the doctor since he is never taken into a factory as a student and taught how a large part of the population spend the greater part of their days. We therefore welcome the statement by this committee that the medical student is not expected to become an expert in occupational diseases. It is much more important that he should acquire knowledge and understanding of the social problems relating to industry and be able to recognize the mental and physical response of his patient to fatigue, overwork, monotony, unsuitable hours or type of employment. For this purpose, the practical course in preventive medicine should bring him into personal contact with industrial conditions through visits to factories, and demonstrations of both good and adverse conditions, the latter in industrial museums where such exist. From experience in visiting industrial concerns, it is evident that teaching visits would be greatly welcomed, both by the management and the workers. Surprise is expressed that such visits have not taken place before; and they would certainly result in industry placing much greater trust and reliance in the medical profession.

Not only is the environmental side of this report important, but it shows that preventive medicine can be practised extensively in the factory. The value of mass miniature radiography is already established. By this means the unsuspected case of pulmonary tuberculosis can be found and treated, and at the same time be removed from contact with healthy individuals who are thus protected from the most deadly single disease which attacks people at the prime of their working life. The importance of rehabilitation is also recognized. It is to be hoped that experiments such as the 'sheltered shop' in which the hospital officer visits the shop and cooperates with the engineer in restoring an injured man to work will be greatly extended. It is important that medical students also see the patient here, as well as in the clinic and hospital. We must learn to understand the full implications of treatment, after-care and restoration to employment. 